\title{
Effect of different nutritional regimens before ovulation on plasma concentrations of metabolic and reproductive hormones and oocyte maturation in gilts
}

\author{
E. M. Ferguson ${ }^{1 *}$, C. J. Ashworth ${ }^{1}$, S. A. Edwards' ${ }^{2}$, N. Hawkins ${ }^{3}$, \\ N. Hepburn ${ }^{4}$ and M. G. Hunter ${ }^{3}$ \\ ${ }^{1}$ SAC, Animal Biology Division, Bucksburn, Aberdeen AB21 9YA, UK; ${ }^{2}$ University of Newcastle, School \\ of Agriculture Food and Rural Development, Newcastle NE1 $7 R U$, UK; ${ }^{3}$ University of Nottingham, \\ Division of Animal Physiology, Sutton Bonington, Loughborough LE12 5RD, UK; and ${ }^{4}$ University of \\ Aberdeen, School of Biological Sciences, Aberdeen AB24 2TZ, UK
}

This study examined the effect of feeding either a maintenance $\left(1.35 \mathrm{~kg} \mathrm{day}^{-1}\right)$ or high $\left(3.5 \mathrm{~kg} \mathrm{day}^{-1}\right)$ plane of nutrition for 19 days after oestrus on oocyte maturity and both reproductive and metabolic hormone concentrations in gilts. Blood samples were collected each day from oestrus until slaughter on day 19 and during two pulse bleeds (15 min samples for $8 \mathrm{~h}$ ) conducted on day 12 and day 18. After slaughter, oocytes were recovered from the presumed ovulatory population of follicles, matured in vitro for $46 \pm 2 \mathrm{~h}$ with $10 \%$ of their own follicular fluid, and then fixed and stained to determine the stage of nuclear maturation of the oocyte. Gilts fed the high diet had a higher proportion of oocytes that reached metaphase II than gilts fed the maintenance diet $(88.3 \pm 2.71 \%$ versus $68.2 \pm 6.48 \% ; P=0.013)$. Circulating concentrations of insulin-like growth hormone I (IGF-I) and the number of LH pulses were lower $(P<0.05)$ in gilts fed the maintenance diet compared with gilts fed the high diet on day 12 and day 18. Mean oestradiol and progesterone concentrations were higher $(P<0.05)$ for gilts fed the maintenance diet compared with gilts fed the high diet. Leptin concentrations were also higher on day 19 in gilts fed the high diet $\left(2.16 \pm 0.26 \mathrm{ng} \mathrm{ml}^{-1}(n=9)\right.$ versus $3.20 \pm 0.32 \quad(n=11)$, $P=0.025)$. The results of this study indicate that improved oocyte quality (increased proportion of oocytes that reached metaphase II) is associated with a number of changes in reproductive and metabolic hormones. Further studies are required to indicate which hormonal mechanism may, in turn, lead to increased embryo survival and eventual litter size.

\section{Introduction}

The profitability of pig production is dependent on the number of pigs weaned per sow per year. Approximately $30 \%$ of oocytes shed at ovulation are not represented by piglets at birth, a source of great economic loss for the pig industry. Most of the prenatal loss occurs during the first month of pregnancy. Pope and First (1985) showed that only $75 \%$ of pig blastocysts present on day 9 of pregnancy survive until day 25. A high proportion of the loss occurs at about the time of maternal recognition of pregnancy and implantation (days 12-18 of gestation). At the time of maternal recognition of pregnancy, there is an asynchronous array of developmental stages within the blastocyst population (Pope et al., 1986) and it is suggested that the more advanced embryos bring about

*Present address: Assisted Reproduction Unit, Department of Obstetrics and Gynaecology, Aberdeen Maternity Hospital, Foresterhill, Aberdeen AB25 2ZO, UK

Email: e.ferguson@abdn.ac.uk changes to the uterine environment that are detrimental to less mature embryos.

Several studies have demonstrated that nutritional modification both before and after conception influence circulating concentrations of both metabolic and reproductive hormones and prenatal survival. Although nutritional regimens after mating can have an effect, recent data indicate that modifications to the nutritional regimen before mating may have a greater impact on embryo survival and on uniformity of size within litter than the diet after mating (Ashworth et al., 1999a,b). Meishan gilts given a high diet before mating had a higher ovulation rate, higher embryo survival on day 12 of gestation, increased blastocyst size and a reduction in within litter diversity in blastocyst surface area (Ashworth et al., 1999a,b). Several authors have suggested that there is a link between oocyte quality and embryo survival. Primiparous sows fed to appetite from day 21 to day 28 of lactation had a higher proportion of oocytes that were able to develop in vitro to metaphase II of meiosis than oocytes in sows in which feed intake was restricted 
(Zak et al., 1997b). Primiparous sows fed to appetite before weaning also had greater prenatal survival by day 28 of pregnancy (Zak et al., 1997a). This finding indicates that oocyte quality may be a determinant of embryo survival. The improved oocyte maturation is likely to have been associated with an alteration in follicular fluid composition. Another study in primiparous sows confirmed that follicular fluid composition can be altered by changing lysine intake during lactation (Yang et al., 2000). A higher proportion of oocytes matured with the follicular fluid collected from sows fed the medium to high lysine diet reached metaphase II (Yang et al., 2000). These observations lend support to the hypothesis that oocyte quality and maturation is a major determinant of the future developmental potential of the embryo (for example, see Zak et al., 1997a,b; Moor and Dai, 2001).

Evidence is accumulating for hormonal mechanisms that may be involved in improving oocyte quality and embryo survival. It is well known that increasing feed intake and ad libitum feeding of gilts or sows for 1114 days before ovulation, a process known as flushing, increases ovulation rate (Cox et al., 1987; Flowers et al., 1989; Zak et al., 1997a; Ashworth et al., 1999a). However, it is not known whether this increase is a response to a higher intake per se or to an increased intake of a specific nutrient. It is proposed that the mechanism responsible for the flushing response is an increase in IGF-I release and increased clearance of steroids by the liver, which would mediate effects on oocyte maturation. Feed intake is positively correlated with liver mass (Pickard, 1996) and portal blood flow is higher in gilts fed $3 \mathrm{~kg}$ day ${ }^{-1}$ compared with control gilts fed $1 \mathrm{~kg} \mathrm{day}^{-1}$ (Prime and Symonds, 1993), indicating that gilts on a high feed intake may have a greater capacity to metabolize steroids. A reduction in circulating steroid concentrations would result in a decrease in the negative feedback on the hypothalamus-pituitary axis leading to an increase in gonadotrophin release which may act to modulate follicle development and alter follicular fluid composition.

The objectives of the present study were to investigate whether nutritional regimens applied before mating shown to improve prenatal survival in Meishan gilts also have reproductive benefits in indigenous European breeds. The hypothesis for this study is that nutritional regimens that increase embryo survival do so by increasing oocyte maturation. This study also determined changes in circulating reproductive and metabolic hormones that occur in response to nutritional regimens which may shed light on possible hormonal mechanisms mediating any nutritional effects on oocyte maturation.

\section{Materials and Methods}

All animal procedures were conducted at the University of Nottingham in accordance with the Animals (Scientific Procedures) Act (1986) following ethical approval.

\section{Experimental animals}

Twenty-four $F_{1}$ Large White $\times$ Landrace crossbred gilts were obtained from JSR Healthbred Ltd (Driffield). Puberty was attained when the gilts were approximately 180 days old and weighed $105 \mathrm{~kg}$. The gilts were housed in straw pens in groups of four for the whole experiment except during recovery from surgery, when they were penned individually. All gilts were fed $2.3 \mathrm{~kg} \mathrm{day}^{-1}$ of a complete diet supplying $15.2 \%$ crude protein and 13.6 MJ digestible energy (DE) $\mathrm{kg}^{-1}$ until the beginning of the third oestrous cycle. The experimental feeding regimens were then applied during the third oestrous cycle from the day after the first detection of onset of oestrus (day 1 , oestrus=day 0 ) until the animals were killed. Gilts were examined once each day for the onset of standing oestrus before puberty and during subsequent oestrous cycles using direct exposure to a vasectomized boar for $15 \mathrm{~min}$. After one oestrous cycle of normal duration (19-22 days), the cycles of the gilts were synchronized by administration of the synthetic progestagen altrenogest (Regumate, Intervet UK Ltd, Milton Keynes) during the second oestrous cycle. Altrenogest was administered via spray application on the feed ration for 16-18 days. Between day 2 and day 13 of the second oestrous cycle, all gilts underwent surgical insertion of a cannula and vascular access port (VAP, Uno Roestvastaal Bv, Holland) under general anaesthesia. Gilts were given an i.m. injection of both azaperone BP (40 mg ml$~^{-1}$ ) at a dose of $3.3 \mathrm{mg} \mathrm{kg}^{-1}$ body weight and atropine $\left(4.3 \mu \mathrm{g} \mathrm{kg}^{-1}\right)$ approximately 20 min before induction of anaesthesia. Anaesthesia was induced with thiopentone sodium $\left(9 \mathrm{mg} \mathrm{kg}^{-1}\right)$ via an i.v. injection into an ear vein via a 20 gauge butterfly needle. Anaesthesia was maintained with $\mathrm{O}_{2} 8 \mathrm{I}, \mathrm{N}_{2} \mathrm{O} 4 \mathrm{I}$ and halothane at $1.0-1.5 \%$ via a $12 \mathrm{~mm}$ endotracheal tube into the trachea. The cannula was placed approximately $30 \mathrm{~cm}$ into the cephalic vein, exteriorized behind the ear and attached to a vascular access port, which was placed in a s.c. pocket under the skin. Feed was withheld on the day of surgery only. From 2 weeks after surgery, the ports were flushed each week with physiological saline containing sodium heparin $\left(1000 \mathrm{iu} \mathrm{ml} \mathrm{m}^{-1}\right)$ and $10 \%(\mathrm{w} / \mathrm{v})$ terramycin q50 until sampling began. Once sampling began ports were flushed with physiological saline containing sodium heparin $\left(1000 \mathrm{iu} \mathrm{m}^{-1}\right)$. Emla cream 5\% (Lidocaine $25 \mathrm{mg} \mathrm{g}^{-1}$ and prilocaine $25 \mathrm{mg}$ $\mathrm{g}^{-1}$, Astra pharmaceuticals Ltd, Hertfordshire), a local anaesthetic, was applied to the area of the skin over the VAP and left for 20 min before flushing or blood collection began from the port.

\section{Body weight and scanning}

All gilts were weighed at puberty, at the onset of the third oestrous cycle and at slaughter. Back fat thickness was measured at the P2 position using an 
ultrasound probe (Aloka Co Ltd). The gilts were allocated randomly to receive either $1.35 \mathrm{~kg} \mathrm{day}^{-1}$ (maintenance, $n=12)$ or $3.5 \mathrm{~kg} \mathrm{day}^{-1}(2.6 \times$ maintenance, $n=12)$ of a complete diet supplying $15.2 \%$ crude protein and $13.6 \mathrm{MJ} \mathrm{DE} \mathrm{kg}{ }^{-1}$. The feed requirement for maintenance was calculated according to the following equation: requirement $\left(\mathrm{MJ} \mathrm{DE}\right.$ day $\left.^{-1}\right)=0.462 \times$ live weight $^{0.75}(\mathrm{NRC}$, 1998).

\section{Collection of blood samples}

Treatment regimens began on the first day after standing oestrus was detected at the onset of the third oestrous cycle, which was classed as day 1. Daily blood samples of $10 \mathrm{ml}$ were collected at the same time each day at approximately $2 \mathrm{~h}$ after feeding during the treatment cycle for measurement of steroids and leptin. Frequent blood samples were collected on day 12 (luteal phase) and day 18 (follicular phase) of the treatment cycle. Blood samples were collected at $1 \mathrm{~h}$ intervals for the first $2 \mathrm{~h}$ before feeding for a pre-prandial measurement, and then at $15 \mathrm{~min}$ intervals for $6 \mathrm{~h}$ after feeding for measurement of insulin and glucose concentration and then at $1 \mathrm{~h}$ intervals for IGF-I concentrations. For determination of $\mathrm{LH}$ and FSH concentrations, blood samples were collected at $15 \mathrm{~min}$ intervals for $8 \mathrm{~h}$. Blood samples were collected in heparinized tubes, except for the glucose samples, which were collected into tubes containing an anticoagulant and fluoride salt, as a glycolysis inhibitor (Sarstedt Ltd, Wexford). Blood samples were centrifuged at $2200 \mathrm{~g}$ for 10-15 min; plasma was removed and stored at $-20^{\circ} \mathrm{C}$.

\section{Ovary and oocyte recovery}

Gilts were killed on day 19 of the treatment cycle. The ovaries were collected and maintained at $37^{\circ} \mathrm{C}$ in Hepes-buffered TCM-199 medium (Sigma, Poole) supplemented with $0.2 \%(\mathrm{w} / \mathrm{v})$ polyvinyl alcohol and penicillin (100 iu $\mathrm{ml}^{-1}$ ) and streptomycin $\left(10 \mu \mathrm{g} \mathrm{ml}^{-1}\right)$ (Hepes TCM-199). Whenever possible, oocytes were recovered from the largest 14 or 17 follicles from each gilt fed the maintenance or the high diet, respectively. These numbers were selected on the assumption that they would reflect the minimum ovulatory population in both groups (determined from preliminary studies using contemporary animals of the same genotype). The assumption was that the largest follicles present in the late follicular phase represent the presumptive ovulatory population (Foxcroft et al., 1987). However, in two animals on both the maintenance and high diets, oocytes could be collected from only 12,13,15 and 16 follicles, respectively. Follicles were defined as small if $\leqslant 5 \mathrm{~mm}$ in diameter, medium if $>5 \mathrm{~mm} \leqslant 7 \mathrm{~mm}$ in diameter and large if $>7 \mathrm{~mm}$ in diameter. All follicles sampled were $>4 \mathrm{~mm}$ in diameter, and only 16 follicles in total were categorized as small. Each of the largest follicles in the presumed minimum ovulatory population was dissected and the diameter measured. The follicles were punctured and the cumulus-oocyte complexes were located and collected in a Petri dish containing Hepes TCM-199. The fluid from each follicle was collected in a Hamilton syringe; the volume was measured and fluid was stored in a separate sterile Eppendorf tube. Pools of follicular fluid comprising $10 \mu \mathrm{l}$ of fluid from each follicle sampled from each animal were established. The remaining fluid was stored at $-20^{\circ} \mathrm{C}$. Oestradiol concentrations were measured in follicular fluid collected from individual follicles and a mean oestradiol concentration was calculated for each pig. The pooled fluid sample was centrifuged at $20 \boldsymbol{g}$ for $2 \mathrm{~min}$ to remove any debris and added to the maturation medium to give a final concentration of $10 \%$. All oocytes were washed twice in Hepes-buffered TCM-199 supplemented with $0.2 \%$ polyvinyl alcohol and washed twice in maturation medium. The medium used for maturation consisted of bicarbonated buffered M199 (without L-glutamine, Sigma), $100 \mathrm{ng} \mathrm{ml}^{-1}$ of pLH and pFSH (AFP10640B and AFP12389A National Hormone and Pituitary Program, CA), 100 iu penicillin $\mathrm{ml}^{-1}, 10 \mu \mathrm{g}$ streptomycin $\mathrm{ml}^{-1}$ (Gibco, Paisley) and $10 \%$ follicular fluid from the pooled sample for that gilt (TCM199). The oocytes from each gilt were matured in a $200 \mu \mathrm{l}$ drop of TCM-199 under mineral oil in a Petri dish (Nunc, Scientific Laboratory Supplies Ltd, Nottingham). The number of oocytes per drop varied between 11 and 17 depending on whether the full number of oocytes was collected from each gilt. The oocytes were matured for $46 \pm 2 \mathrm{~h}$ at $37^{\circ} \mathrm{C}$ under humidified $5 \% \mathrm{CO}_{2}$ in air.

At the end of maturation, oocytes were denuded of cumulus cells by placing them in drops of TCM-199 containing $0.1 \%(\mathrm{w} / \mathrm{v})$ hyaluronidase (Sigma) for $<1 \mathrm{~min}$. The oocytes were fixed for $48 \mathrm{~h}$ in fixative containing ethanol:acetic acid (3:1). The nuclear status of oocytes (germinal vesicle, germinal vesicle breakdown, metaphase I or metaphase II) was identified by examination under a phase-contrast microscope after staining with $1 \%(\mathrm{w} / \mathrm{v})$ lacmoid in $45 \%(\mathrm{w} / \mathrm{v})$ acetic acid solution as described by Hunter and Polge (1966).

\section{Plasma analysis}

IGF-I. Plasma IGF-I was separated from its binding proteins by acidification followed by size exclusion chromatography in acid on an HPLC system (Gilson 231, Gilson Medical electronics, Middleton) based on a method by Owens et al. (1990). The extracted acid solution containing IGF-I was neutralized using Trisbuffer. IGF-I concentrations were measured using a ${ }^{125}$ I-labelled IGF-I double antibody radioimmunoassay (Owens et al., 1990). The radioimmunoassay method was modified by using the neutralized mobile phase buffer to make-up IGF-I standards and $400 \mu$ I of sample or standards was assayed in duplicate rather than in 
$200 \mu \mathrm{l}$. The first antibody was diluted at 1 in 3500 and the second at 1 in 80 . The assay uses recombinant human IGF-I, anti-human IGF-I polyclonal antiserum (rabbit) obtained from GroPep Ltd (Adelaide BC), normal rabbit serum and donkey anti-rabbit $\lg G$ obtained from Diagnostics Scotland (Law Hospital, Scotland). The [ $\left.{ }^{125} \mathrm{I}\right]$ was prepared using the chloramine T method (Fraker and Speck, 1978). The intra- and interassay coefficients of variation were 9.7 and $14.0 \%$, respectively. The limit of the assay sensitivity was $21 \mathrm{ng} \mathrm{ml}^{-1}$.

Glucose. Glucose concentrations were determined using an enzymatic (glucose oxidase peroxidase) colorimetric method on a BMD/Hitachi 705 auto-analyser (Lewes). The kit was supplied by Boehringer Mannheim $\mathrm{GmbH}$ (Lewes). The limit of the assay sensitivity was $0.88 \mathrm{mmol} \mathrm{I}^{-1}$. The intra- and interassay coefficients of variation were 1.6 and $3.7 \%$, respectively.

Oestradiol. Plasma concentrations of oestradiol were measured using an extraction procedure involving diethyl ether and then an $\left.{ }^{125} \mathrm{I}\right]$-oestradiol radioimmunoassay method described by Mann et al. (1995). The assay was modified slightly and the antibody-bound and free oestradiol were separated by charcoal rather than by the addition of a second antibody (Ashworth et al., 1996). The limit of the assay sensitivity was $5.0 \mathrm{pg} \mathrm{ml}^{-1}$. The intra- and interassay coefficients of variation were 6.1 and $12.3 \%$, respectively.

Oestradiol in follicular fluid. Oestradiol concentrations in follicular fluid were measured using an assay in which the samples were not extracted. The $\left[{ }^{125} \mathrm{I}\right]$-oestradiol radioimmunoassay was based on the method by Webb et al. (1985). The minimum limit of sensitivity was $78 \mathrm{pg} \mathrm{ml}^{-1}$ and the mean intra- and interassay coefficients of variation were 7.7 and $10.3 \%$, respectively.

Insulin. Plasma insulin concentrations were measured using an ${ }^{125}$ I-labelled insulin double antibody radioimmunoassay based on the method of Starr et al. (1979). The assay was modified to use pig insulin (I-3505, 24 iu mg) obtained from Sigma and guinea-pig antipig insulin, normal guinea-pig serum and sheep-antiguinea-pig IgG obtained from Diagnostic Scotland. The ${ }^{125}$ l-labelled pig insulin solution was prepared using the chloramine T method (Fraker and Speck, 1978). The limit of sensitivity was $1.657 \mu \mathrm{iu} \mathrm{ml} \mathrm{m}^{-1}$ and the intra- and interassay coefficients of variation were 8.3 and $9.4 \%$, respectively.

$\mathrm{LH}$. Plasma concentrations of $\mathrm{LH}$ were measured in duplicate by a double antibody radioimmunoassay described by Rensis et al. (1993). The limit of sensitivity was $50 \mathrm{pg} \mathrm{ml}^{-1}$ and the intra- and interassay coefficients of variation were 12.5 and $21.1 \%$, respectively.
FSH. Plasma concentrations of FSH were determined in duplicate by a double antibody radioimmunoassay described by Rensis et al. (1993). The limit of sensitivity was $0.58 \mathrm{ng} \mathrm{ml}^{-1}$ and the intra- and interassay coefficients of variation were 11.6 and $14.0 \%$, respectively.

Progesterone. Plasma progesterone concentrations were determined in duplicate by petroleum ether extraction before radioimmunoassay with ${ }^{125}$ I using the method described by Hunter et al. (1986). The limit of sensitivity was $0.1 \mathrm{ng} \mathrm{m}^{-1}$ and the intra- and interassay coefficients of variation were 11.4 and $18.5 \%$, respectively.

Leptin. Plasma leptin concentrations were determined in duplicate using a commercially available multi-species double antibody radioimmunoassay (Linco Research, Missouri). The kit consisted of ${ }^{125}$ I-labelled recombinant human leptin, human leptin standards and guinea-pig anti-leptin antibody. The antibody raised against human leptin displays a $67 \%$ crossreactivity to pig leptin (Linco Research). The limit of sensitivity was $1 \mathrm{ng} \mathrm{ml}^{-1}$. Leptin was expressed as $\mathrm{ng} \mathrm{ml}^{-1}$ human equivalent (HE). The intra-assay coefficient of variation was $3.7 \%$.

\section{Statistical analyses}

All data were analysed using the Genstat statistical package (Genstat 6: Committee of the Statistics Department, Rothamsted Experimental Station, Harpenden). All dependent variables were checked for normality using histogram plots. Values were transformed by arc-sines of the square root of the proportion or were transformed by log or square root if needed. Ovulation rate and oocyte maturation rates were compared between treatment groups by one-way ANOVA. One gilt was removed from the maintenance group because of illness. Animals were removed from analysis for oocyte and follicle and reproductive data if circulating oestradiol concentrations had not significantly increased by day 19 (two pigs from the maintenance diet group and one from the high diet group were removed). If plasma oestradiol concentration was significantly lower on day 19 than on days $17-18$ it was assumed that the LH surge had occurred in these animals so they were also removed (two pigs from the high diet group). One animal from the high diet group was also removed because it had already ovulated at the time of slaughter.

Steroid and metabolic hormone concentrations were analysed in a statistical model, which included diet and day of the cycle/period (luteal and follicular phase) as the treatment effect and gilt as a block.

Regression analysis was used to determine relationships between ovulation rate, oocyte maturation rate (the proportion of oocytes maturing to metaphase II) and endocrine characteristics. Relationships were examined within treatment groups. 
For insulin and glucose data the post-prandial area under the curve (AUC) was calculated from the prefeeding baseline (mean preprandial concentration) until the time after feeding when the value returned to the preprandial concentration. These data were analysed by ANOVA.

During the $8 \mathrm{~h}$ sampling period in the luteal and follicular phase, LH pulses were defined by the following criteria: (i) an increase of at least two standard deviations above the preceding point; (ii) occurrence of the peak value within two sampling periods of the base point; and (iii) presence of at least one point on the descending shoulder of the pulse greater than the base point. The pulse amplitude was calculated by the peak concentration minus the base point. $\mathrm{LH}$ and $\mathrm{FSH}$ data were analysed by ANOVA.

\section{Results}

Feed intake, body weight and back fat changes

All gilts consumed their allocation when given the maintenance diet, but some feed refusals were recorded on the high plane of nutrition. Average daily feed intake for gilts on the maintenance and high diet was $1.35 \mathrm{~kg}$ and $3.42 \pm 0.008 \mathrm{~kg}$, respectively, during the 19 days of treatment.

The weight and back fat measurements did not differ between gilts allocated to the two treatment groups. The average weight of gilts was $126 \pm 2.04 \mathrm{~kg}$ and back fat was $16 \pm 0.19 \mathrm{~mm}$ compared with $124 \pm 1.74 \mathrm{~kg}$ and $16 \pm 0.5 \mathrm{~mm}$ for gilts at the start of the treatment cycle on the maintenance and high diet, respectively. However, after 19 days on the high diet there was a significant increase in weight $(P<0.001)$ and back fat $(P=0.015)$ with values of $138 \pm 1.83 \mathrm{~kg}$ and $17.0 \pm$ $0.34 \mathrm{~mm}$, respectively. For gilts fed the maintenance diet there was no change in weight and back fat values by the end of the treatment cycle with values of $126 \pm 1.78 \mathrm{~kg}$ and $15.8 \pm 0.23 \mathrm{~mm}$, respectively.

\section{Oocyte maturation and follicular fluid concentrations}

The final number of gilts included in the maintenance and high diet group was nine and eight, respectively. At the time the animals were killed, the ovaries of gilts fed the high diet were heavier than those of gilts fed the maintenance diet $(12.4 \pm 0.5 \mathrm{~g}$ versus $10.9 \pm 0.46 \mathrm{~g}$, respectively $(P<0.05))$, reflecting their larger minimum ovulatory population (17.8 \pm 0.67 follicles compared with $14.8 \pm 0.60$ follicles, respectively).

The distribution of small, medium and large follicles in the presumed ovulatory population was similar for gilts on both nutritional regimens (Fig. 1).

The percentages of oocytes that reached the different stages of nuclear maturation are shown (Table 1). A significantly higher percentage of oocytes from gilts

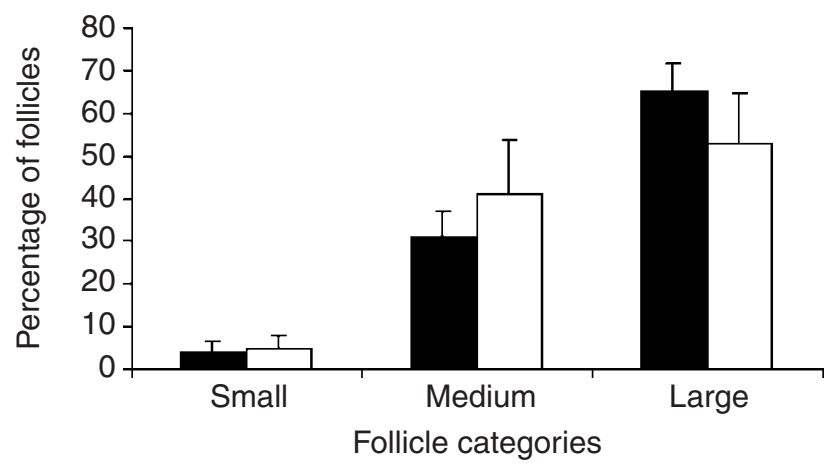

Fig. 1. The percentage of small ( $\leqslant 5 \mathrm{~mm}$ in diameter; $n=16)$, medium ( $>5 \mathrm{~mm}$ and $\leqslant 7 \mathrm{~mm}$ in diameter; $n=102$ ) and large ( $>7 \mathrm{~mm}$ in diameter; $n=157$ ) follicles within the presumed ovulatory population for gilts on the maintenance $(\mathbf{\square})$ and high ( $\square$ ) diet. Data are expressed as mean \pm SEM.

Table 1. Percentage of oocytes at the different stages of nuclear maturation from gilts fed the maintenance and high diet

\begin{tabular}{lcc}
\hline & \multicolumn{2}{c}{ Treatment diet } \\
\cline { 2 - 3 } & Maintenance $(n=92)$ & High $(n=131)$ \\
\hline Number of oocytes & 92 & 131 \\
Stage of nuclear maturation & & $7.0 \pm 1.73$ \\
$\quad$ Germinal vesicle (\%) & $10.3 \pm 4.2$ & 0 \\
Germinal vesicle & 0 & $1.5 \pm 0.35^{\mathrm{b}}$ \\
$\quad$ breakdown (\%) & & $88.3 \pm 2.71^{\mathrm{c}}$ \\
Metaphase I $(\%)$ & $21.7 \pm 4.14^{\mathrm{a}}$ & $2.5 \pm 0.4$ \\
Metaphase II $(\%)$ & $68.2 \pm 6.48^{\mathrm{b}}$ & \\
Degenerated $(\%)$ & $1.6 \pm 0.2$ &
\end{tabular}

Maintenance $(n=9)$ and high $(n=8)$ diet groups.

Values with different superscripts within the same row are significantly different ${ }^{\mathrm{ab}} P<0.001$, bc $P=0.015$.

on the high diet reached the final stage of maturation (metaphase II) compared with oocytes from gilts fed the maintenance diet. The percentage of degenerated oocytes was similar with values of $1.6 \pm 0.2 \%$ versus $2.5 \pm 0.4 \%$ for gilts fed the maintenance and high diet, respectively.

Follicular fluid concentrations of oestradiol were higher in gilts fed the high diet than in gilts fed the maintenance diet $\left(332 \pm 70 \mathrm{ng} \mathrm{ml}^{-1}\right.$ versus $173 \pm$ $21.9 \mathrm{ng} \mathrm{ml}^{-1}, P=0.046$ ). Average follicle diameter and fluid volume for gilts on the maintenance and high diet were $6.96 \pm 0.28 \mathrm{~mm}$ versus $6.90 \pm 0.22 \mathrm{~mm}$ and $90 \pm$ $11.8 \mu \mathrm{l}$ versus $104 \pm 10.9 \mu \mathrm{l}$, respectively.

\section{Reproductive hormone and intermediary metabolite concentrations}

Daily blood samples were obtained from 20 gilts and intensive samples obtained from a maximum of 19 gilts. These numbers reflect the number of vascular access ports that remained patent throughout most of the 


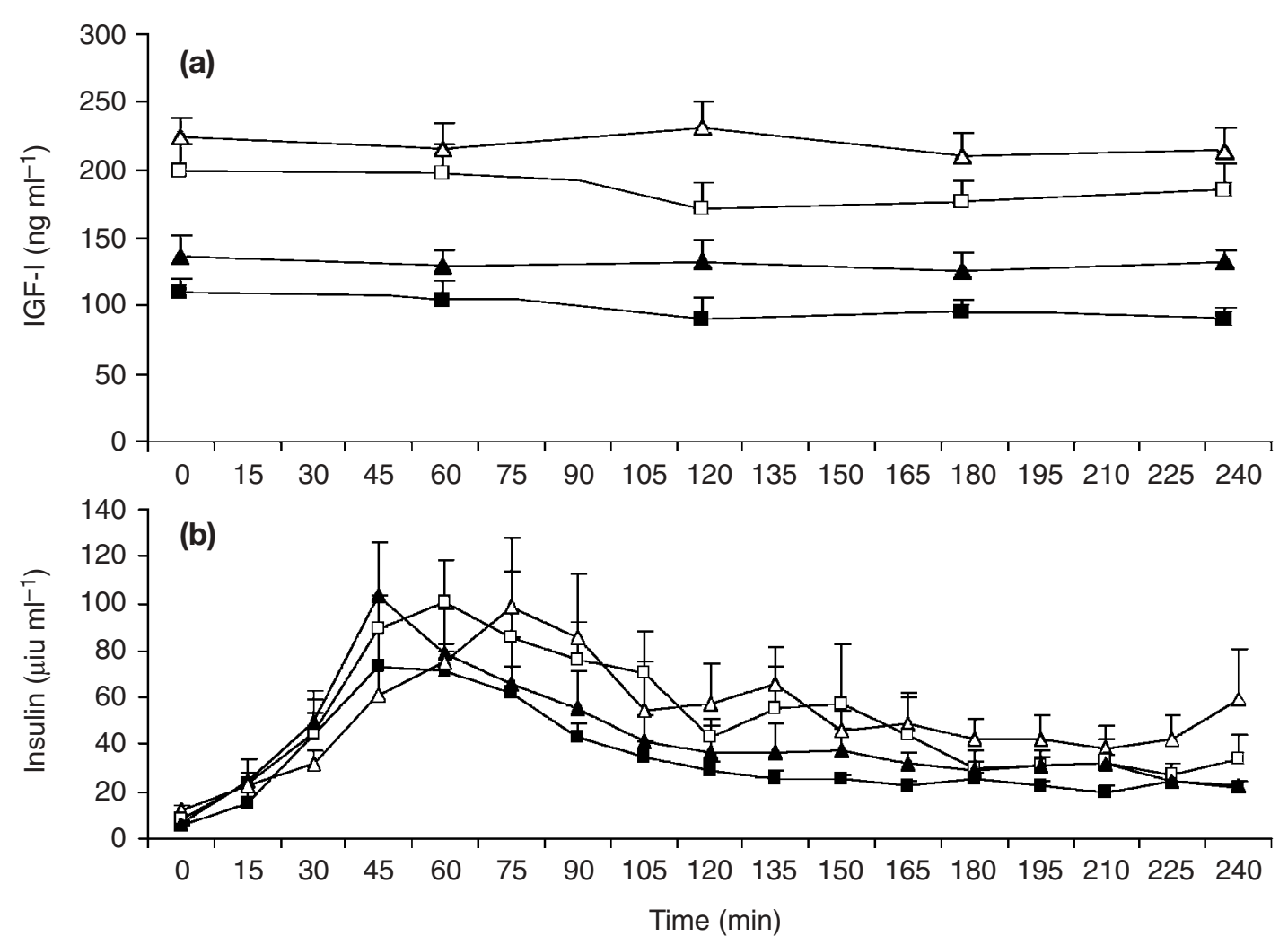

Fig. 2. (a) Insulin-like growth factor I (IGF-I) and (b) insulin profiles during the luteal $(\square)$ and follicular phase $(\triangle)$ for gilts on the maintenance $(\boldsymbol{\square})$ and high $(\square)$ diet. Data are expressed as mean \pm SEM. Time 0 represents the time when the gilts were fed and the IGF-I or insulin concentration at this point is the mean pre-prandial concentration over 2 h before feeding $(n=8-10)$.

sampling period. However, for measurement of reproductive hormones from daily and intensive samples, results were used from only a maximum of 16 gilts (four gilts were removed because they were not at an appropriate stage of the cycle at the time of slaughter).

\section{IGF-I}

Plasma concentrations of IGF-I remained similar throughout the $6 \mathrm{~h}$ sampling period both before and after feeding in both the luteal and follicular phase (Fig. 2). During the luteal phase, the mean IGF-I concentration in maintenance fed gilts $(n=10)$ was lower, with values of $102 \pm 32 \mathrm{ng} \mathrm{ml}^{-1}$ versus $190 \pm 46 \mathrm{ng} \mathrm{ml}^{-1}, P<0.001$ compared with gilts fed the high diet $(n=8)$, respectively (Fig. 2a). Similarly, follicular phase concentrations were also lower for gilts on the maintenance diet $(131 \pm 42 \mathrm{ng}$ $\mathrm{ml}^{-1}$ versus $\left.221 \pm 38 \mathrm{ng} \mathrm{ml}^{-1}, \quad P<0.001\right)$ compared with gilts on the high diet (Fig. 2a).

Regression analysis revealed a positive relationship between mean IGF-I concentration per gilt during the follicular phase and the proportion of oocytes that reached metaphase II for both nutritional regimens (Fig. 3).

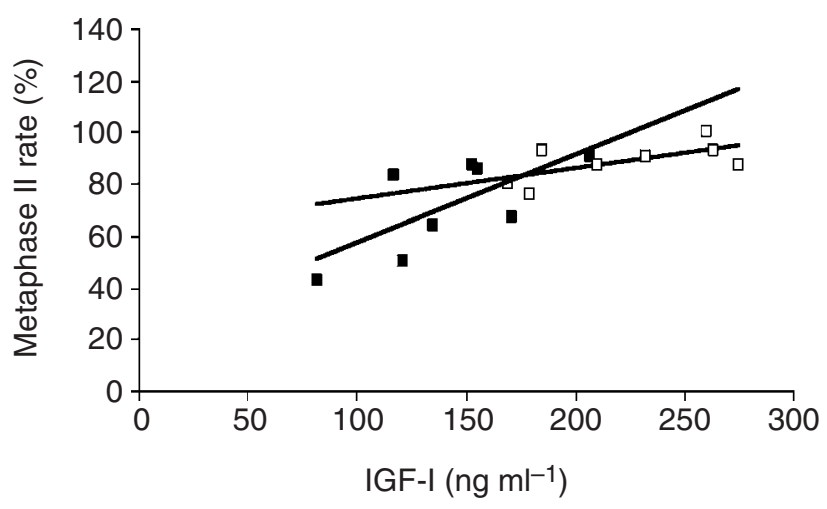

Fig. 3. The relationship between mean plasma insulin-like growth factor I (IGF-I) concentration and the percentage of oocytes that reached metaphase II (follicular period) for gilts on the maintenance (घ) $(n=8, r=0.62, P=0.096)$ and high $(\square) \operatorname{diet}(n=8, r=0.71$, $P=0.049)$.

\section{$L H$ and $F S H$}

There were fewer $\mathrm{LH}$ pulses during both $8 \mathrm{~h}$ sampling periods in gilts fed the maintenance diet (Table 2). Mean LH pulse amplitude during the luteal and follicular phase was not significantly different between treatments, but the pulse amplitude was lower $(P<0.001)$ in the 
Table 2. Effect of feeding a maintenance or high diet on the number of LH pulses, LH pulse amplitude and mean FSH concentration during the luteal and follicular phase

\begin{tabular}{|c|c|c|c|c|c|c|}
\hline \multirow[b]{2}{*}{ Stage of oestrous cycle } & \multicolumn{2}{|c|}{ Maintenance diet } & \multicolumn{2}{|c|}{ High diet } & \multicolumn{2}{|c|}{ Effect of: } \\
\hline & Luteal $(n=8)$ & Follicular $(n=6)$ & Luteal $(n=8)$ & Follicular $(n=8)$ & Diet & Cycle stage \\
\hline Number of LH pulses per $8 \mathrm{~h}$ & $0.81 \pm 0.2^{\mathrm{a}}$ & $2.75 \pm 0.3^{\mathrm{a}}$ & $1.50 \pm 0.31^{b}$ & $3.69 \pm 0.24^{b}$ & $P=0.003$ & $P<0.001$ \\
\hline LH pulse amplitude (ng ml $\left.{ }^{-1}\right)$ & $0.88 \pm 0.03$ & $0.13 \pm 0.02$ & $0.67 \pm 0.16$ & $0.18 \pm 0.05$ & NS & $P<0.001$ \\
\hline $\mathrm{FSH}\left(\mathrm{ng} \mathrm{ml} \mathrm{m}^{-1}\right)$ & $1.63 \pm 0.12$ & $0.74 \pm 0.08$ & $1.80 \pm 0.2$ & $0.67 \pm 0.11$ & NS & $P<0.001$ \\
\hline
\end{tabular}

Data are expressed as mean \pm SEM.

${ }^{a b}$ Values with different superscripts are significantly different $(P<0.001)$ between treatments in the same sampling period.

follicular phase for both the maintenance and high diet group (Table 2).

Regression analysis revealed an inverse relationship between the number of $\mathrm{LH}$ pulses and the peak progesterone concentration during the follicular phase for gilts on the maintenance diet $(r=0.72, P=0.043$, $n=8$ ). This relationship was not present in gilts receiving the high diet.

FSH concentrations remained relatively constant during the entire sampling period in both the luteal and follicular phase for both treatment groups. The mean FSH concentration was similar for both treatments during the luteal and follicular phase. Mean FSH concentration was lower in the follicular phase than in the luteal phase for gilts on both the maintenance and high diet $(P<0.001$; Table 2).

\section{Glucose}

Plasma concentrations of glucose were measured in samples collected during frequent sampling periods in the luteal and follicular phase. Preprandial glucose concentrations were similar for gilts on the maintenance and high diets for both sampling periods (luteal phase $4.17 \pm 0.09 \mathrm{mmol} \mathrm{I}^{-1} \quad(n=10)$ versus $4.11 \pm$ $0.11 \mathrm{mmol} \mathrm{I}^{-1}(n=9)$; follicular phase $4.34 \pm 0.08 \mathrm{mmol}$ $\mathrm{I}^{-1} \quad(n=10)$ versus $4.26 \pm 0.09 \mathrm{mmol} \mathrm{I}^{-1} \quad(n=9)$, respectively. The post-prandial AUC was significantly lower for gilts on the high diet compared with gilts on the maintenance diet for both sampling periods (luteal phase $0.61 \pm 0.1 \mathrm{mmol} \mathrm{I}^{-1} \mathrm{~min}^{-1}$ versus $0.96 \pm$ $0.11 \mathrm{mmol} \mathrm{I}^{-1} \mathrm{~min}^{-1} \quad(P=0.042)$; follicular phase $0.59 \pm 0.11 \mathrm{mmol} \mathrm{I}^{-1} \mathrm{~min}^{-1}$ versus $1.40 \pm 0.22 \mathrm{mmol}$ $\mathrm{I}^{-1} \min ^{-1} \quad(P=0.0005)$, respectively). Peak glucose values were similar during the luteal sampling period $\left(6.02 \pm 0.17 \mathrm{mmol} \mathrm{I}^{-1}\right.$ versus $\left.6.01 \pm 0.15 \mathrm{mmol} \mathrm{I}^{-1}\right)$, but were different during the follicular sampling period $\left(7.10 \pm 0.27 \mathrm{mmol} \mathrm{I}^{-1}\right.$ versus $5.53 \pm 0.23 \mathrm{mmol} \mathrm{I}^{-1}$, $P=0.0006)$ for gilts on the maintenance and high diet, respectively.

\section{Insulin}

Preprandial insulin concentrations were significantly lower in maintenance fed gilts during both the luteal and follicular phase (luteal phase $5.3 \pm 0.56 \mu \mathrm{iu} \mathrm{ml^{-1 }}$ $(n=10)$ versus $8.7 \pm 1.19 \mu \mathrm{iu} \mathrm{ml} \mathrm{m}^{-1} \quad(n=9), P=0.015$; follicular phase $6.34 \pm 0.45 \mu \mathrm{iu} \mathrm{ml^{-1 }}(n=10)$ versus $11.58 \pm 2.37 \mu \mathrm{iu} \mathrm{ml^{-1 }}(n=9), P=0.036$, respectively) (Fig. 2b). There were no significant relationships between insulin concentrations before feeding and any of the other measured metabolic or reproductive parameters.

Insulin AUC was lower for gilts fed the maintenance diet (luteal phase $30.4 \pm 3.35 \mu \mathrm{iu} \mathrm{m}{ }^{-1} \min ^{-1} \quad(n=10)$ versus $46 \pm 7.25 \mu \mathrm{iu} \mathrm{ml} \mathrm{m}^{-1} \mathrm{~min}^{-1}(n=10),(P=0.05)$; fol-

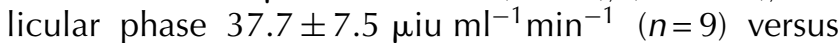
$\left.42.8 \pm 7.7 \mu \mathrm{iu} \mathrm{ml} \mathrm{m}^{-1} \mathrm{~min}^{-1}(n=9)\right)$. The peak insulin concentration during the sampling period in the luteal phase was significantly higher in gilts fed the high diet $(151 \pm 26 \mu \mathrm{iu} \mathrm{ml})^{-1}$ versus $94 \pm 14.75 \mu \mathrm{iu} \mathrm{ml} \mathrm{m}^{-1}$, $P=0.069$ ). Peak insulin concentrations were similar during the follicular phase for both treatment groups $\left(123.4 \pm 19.4 \mu \mathrm{iu} \mathrm{ml}{ }^{-1}\right.$ versus $124 \pm 22.8 \mu \mathrm{iu} \mathrm{ml}{ }^{-1}$ for the maintenance and high diet group, respectively). Peak insulin concentrations occurred slightly later during both sampling periods for gilts fed the high diet (Fig. 2b).

\section{Oestradiol and progesterone}

Plasma concentrations of oestradiol and progesterone determined from blood samples collected each day show that mean oestradiol concentration was $5.74 \pm$ $0.65 \mathrm{pg} \mathrm{ml}^{-1}(n=8)$ for gilts on the maintenance diet versus $4.39 \pm 0.55 \mathrm{pg} \mathrm{ml}^{-1}(n=8),(P<0.001)$ for gilts on the high diet. There was a significant effect of day of oestrous cycle on oestradiol concentration $(P<0.001)$ (Fig. 4). In gilts fed the high diet, there was an inverse relationship between mean oestradiol concentration and the number of $\mathrm{LH}$ pulses $(r=0.74, P=0.036)$. No such trend was observed in gilts fed the maintenance diet.

The mean progesterone concentration over the treatment cycle was $11.9 \pm 1.74 \mathrm{ng} \mathrm{ml}^{-1} \quad(n=8)$ versus $9.55 \pm 1.53 \mathrm{ng} \mathrm{ml}^{-1}(n=8),(P<0.001)$ for gilts fed the maintenance and high diet, respectively. There was also a significant effect of day of oestrous cycle on progesterone concentration $(P<0.001$; Fig. 4). There was an inverse relationship for both treatment groups between the peak plasma progesterone concentration during the oestrous cycle and the proportion of oocytes 


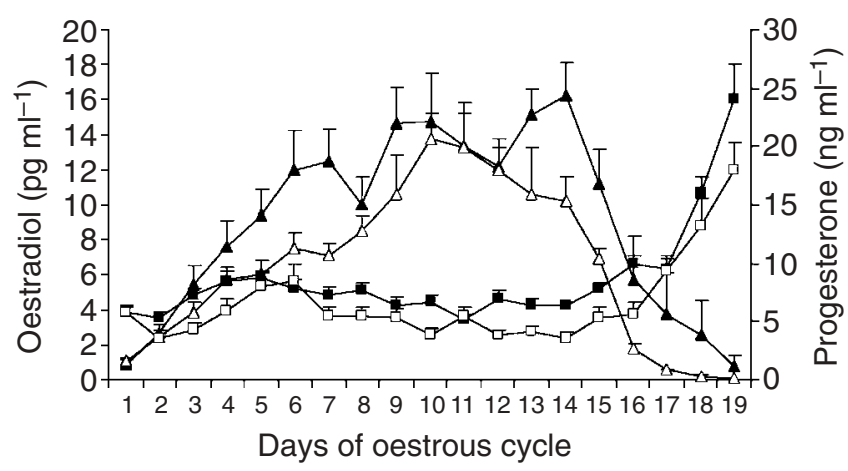

Fig. 4. Mean oestradiol (square symbols) and progesterone (triangles) concentrations throughout the oestrous cycle for gilts fed the maintenance $(\boldsymbol{\square}, \boldsymbol{\Delta} n=8)$ and high $(\square, \triangle, n=8)$ diet.

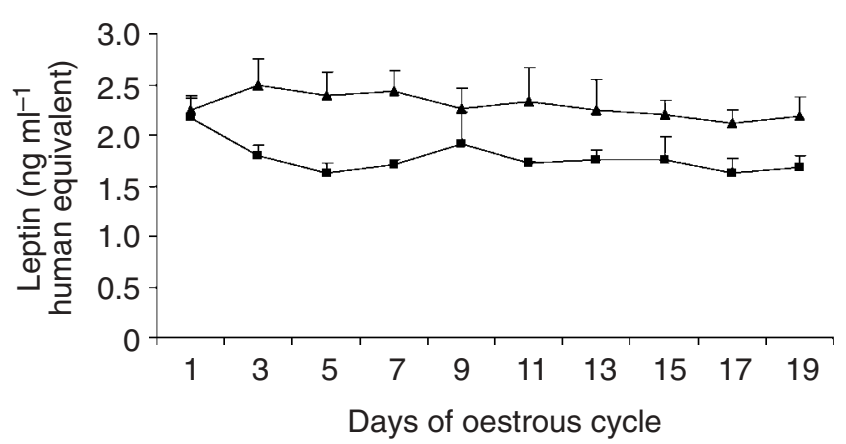

Fig. 5. Mean leptin concentrations for gilts fed a maintenance $(\boldsymbol{\square}, n=6)$ or high $(\boldsymbol{\Lambda}, n=6)$ diet. Data are expressed as mean \pm SEM.

that reached metaphase II which was significant for gilts on the maintenance diet $(r=0.71, P=0.048)$. There was an inverse relationship between mean progesterone concentration and the number of $\mathrm{LH}$ pulses for gilts on the maintenance diet $(r=0.71, P=0.049)$, but not for gilts fed the high diet.

\section{Leptin}

Plasma concentrations of leptin were measured in blood samples collected on alternate days during the 19 day treatment period in six randomly selected gilts from each diet. Plasma leptin concentrations were also measured in day 19 samples collected at slaughter for all gilts. Plasma leptin concentrations increased by day 3 of the treatment cycle in gilts on the high diet and decreased in gilts on the maintenance diet and then remained relatively constant over the rest of the oestrous cycle (Fig. 5). The mean plasma leptin concentration over the whole cycle was $1.78 \pm 0.05 \mathrm{ng} \mathrm{m}^{-1}(n=6)$ versus $2.29 \mathrm{ng} \mathrm{ml}^{-1} \pm 0.04(n=6)(P=0.028)$ for gilts on the maintenance and high diet, respectively. A significant difference in leptin concentration on day 19 of the cycle was also found between the gilts on the high diet and gilts on the maintenance diet with

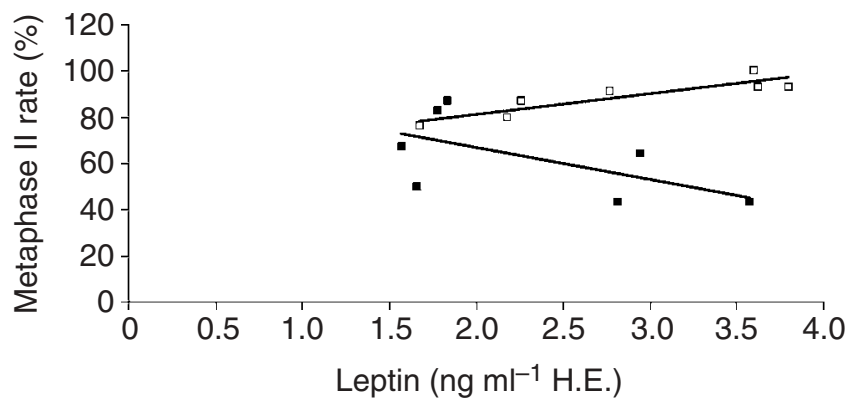

Fig. 6. The relationship between leptin concentration on day 19 of the oestrous cycle and the proportion of oocytes that reached metaphase II for gilts on the maintenance $(\boldsymbol{\square}, r=0.60, n=7, P>0.1)$ and high $(\square, r=0.89, n=7, P=0.006)$ diet.

$2.16 \pm 0.26 \mathrm{ng} \mathrm{ml}^{-1}(n=9)$ versus $3.20 \pm 0.32 \mathrm{ng} \mathrm{m}^{-1}$ $(n=11), P=0.025$, respectively. For gilts on the high diet, a positive relationship was found between plasma leptin concentrations on day 19 and the proportion of oocytes that reached metaphase II $(r=0.90, P=0.006)$ which was not observed ( $r=0.60$, this result was not significant) for gilts on the maintenance diet (Fig. 6).

\section{Discussion}

The results of the present study support the hypothesis that a pre-mating nutritional regimen previously shown to improve embryo survival in Meishan gilts has reproductive benefits too in indigenous European breeds. Increased feed intake for 19 days increased oocyte nuclear maturation by increasing the percentage of oocytes that reached metaphase II and changed follicular fluid composition. In addition, this regimen induced changes in the profile of reproductive and metabolic hormones, which has shed light on the possible hormonal mechanisms mediating nutritional effects on ovarian development.

The findings of the present study contribute to the growing body of evidence that altered nutritional regimens before mating can influence oocyte and follicle characteristics in pigs (Zak et al., 1997b, Quesnel et al., 1998; Yang et al., 2000) and in ruminants (O'Callaghan and Boland, 1999; Comin et al., 2002) and provide new information on possible underlying mechanisms. The findings indicate that increased feed intake may alter the quality of the oocyte directly or alter the follicular fluid composition.

When conducting such studies, it is important to be aware not only of the inherent variation in ovarian development between animals, but also of the possible impact of treatment on ovarian development. However, similar pre-mating dietary treatments to those used in the present study did not affect the duration of the cycle in either Meishan (Ashworth et al., 1999a) or Large White $\times$ Landrace (E. M. Ferguson, M. G. Hunter, 
S. A. Edwards, J. Slevin and C. J. Ashworth, unpublished) gilts. Furthermore, follicle diameter and fluid volume were similar for both treatment groups, indicating that in each group oocytes were collected from follicles that were at similar stages of ovarian development.

The present study demonstrated an increased number of LH pulses, increased follicular fluid concentrations of oestradiol and more oocytes that matured to metaphase II in gilts fed the high diet. In addition to increasing ovulation rate as demonstrated by Flowers et al. (1989), nutritionally induced increases in the number of $\mathrm{LH}$ pulses are important in stimulating follicular development and are also likely to be responsible for the observed increase in follicular fluid oestradiol concentrations. Zak et al. (1997b) and Yang et al. (2000) suggested that altering nutritional intake altered factor(s) within the follicular fluid that contributed to the observed differences in nuclear maturation of the oocyte. Evidence indicating that increased oestradiol in the immediate environment in which the oocyte matures benefits subsequent embryo development comes from data in a bovine in vitro maturation system. The data showed a significant positive correlation between the percentage of hatched blastocysts on day 11 and the average oestradiol concentrations in the follicular fluid (Van de Leemput et al., 1998).

In agreement with the results of many studies in gilts and sows, the follicles in the presumed ovulatory population formed a heterogeneous population in terms of follicle diameter, with variation of 2-3 mm. The follicles in the preovulatory population were distributed among the small, medium or large class and similar percentages of follicles were found in each size class for both nutritional regimens. This result is in contrast to the studies of Zak et al. (1997b), Quesnel et al. (1998) and Yang et al. (2000) in which it was demonstrated that feed restriction before mating reduced the percentage of large follicles and increased the percentage of small follicles in the preovulatory population. The difference in the results between the present study and the three studies discussed above could be explained by the fact that the other studies were conducted in primiparous sows and the feed restriction was applied during lactation. Lactation is a very energy demanding process, generally resulting in loss of body weight and a catabolic state that extends beyond the time of weaning. This leaves little energy for follicle recruitment and growth, which begins again during late lactation in preparation for ovulation after weaning (Britt et al., 1985). Maiden gilts, on the other hand, are usually in an anabolic state and without prior depletion of body reserves.

Metabolic hormones such as insulin, IGF-I, glucose and leptin are likely to be mediators between nutritional status and reproductive performance. Circulating plasma concentrations of IGF-I were reduced in both the luteal and follicular phase of the ovarian cycle in gilts fed the maintenance diet. This finding is consistent with studies in which reduced IGF-I concentrations have been associated with reduced ovulation rates (Cosgrove et al., 1992; Booth et al., 1994; Quensel et al., 1998). An association was found in the present study, for both treatments, between plasma IGF-I concentrations and the percentage of oocytes that reached metaphase II which is similar to findings in humans and in vitro oocyte maturation studies. IGF-I concentration in the follicular fluid at the time of egg recovery was higher in patients who became pregnant after embryo transfer compared with those who failed to establish pregnancy (Mendoza et al., 2002). Pig oocytes matured in vitro in culture medium supplemented with IGF-I had a higher proportion of oocytes that were able to mature (Sirotkin et al., 1998). IGF-I may have a direct effect on the ovary as IGF-I binding sites have been identified on pig granulosa cells (Veldhuis et al., 1985) and are thought to amplify the effects of FSH by increasing steroidogenesis in the follicle. A maintenance level of feeding decreased pre-prandial insulin concentrations and decreased the post-prandial area under the curve during both the luteal and follicular phase. Cox et al. (1987) demonstrated that exogenous administration of insulin during the follicular phase enhanced ovulation rate and increased the episodic release of $\mathrm{LH}$ in gilts. The higher insulin concentrations found with the high plane feeding may thus partially explain the increased ovulation rate. Alterations in circulating concentrations of insulin may alter the secretion of LH and IGF-I or may have a direct effect on the ovary. Insulin binding sites have been identified on pig granulosa cells in vitro (Otani et al., 1985) and insulin has been shown to increase gonadotrophin-stimulated steroidogenesis by granulosa cells in vitro (May and Schomberg, 1981).

As expected, mean circulating concentrations of oestradiol and progesterone were significantly lower in gilts fed the high diet. There is accumulating evidence that increased feed intake reduces circulating steroid concentrations, and increases breakdown of these steroids by the liver resulting from increased liver mass, increased portal blood flow, and stimulation of the biochemical pathways involved in steroid metabolism. Feed intake is positively correlated with liver mass in pigs (Pickard, 1996) and portal blood flow is greater with high plane feeding in gilts (Prime and Symonds, 1993) and in lactating dairy cows (Wieghart et al., 1986). Ashworth et al. (1995) showed that the proportion of total body weight accounted for by liver tissue is higher in gilts receiving a higher level of feed intake. A decreased concentration of circulating steroids may be one of the hormonal mechanisms responsible for improved oocyte maturation rates by its role in increasing the number of $\mathrm{LH}$ pulses through a reduced negative feedback on hypothalamic-pituitary axis.

Leptin concentrations were consistently higher from day 3 of the oestrous cycle in gilts receiving high feed intake, indicating that leptin concentrations are 
altering in response to feed intake rather than in response to changes in back fat depots. This is similar to findings in sheep in which leptin concentrations increased within 5 days after feed intake was increased (Blache et al., 2000). Leptin concentrations remained constant throughout the oestrous cycle which is in contrast to findings in humans: Riad-Gabriel et al. (1998) showed that leptin concentrations were higher during the follicular and early luteal phase of the ovarian cycle and that these changes occurred in the absence of a significant change in body fat mass. In humans, a $10 \%$ reduction in body weight resulted in a 53\% reduction in serum leptin concentrations (Keim et al., 1998). However, overfeeding which did not change body weight also increased serum leptin concentrations by $40 \%$ (Kolaczynski et al., 1996), which is in agreement with our finding indicating that leptin secretion is regulated by factors other than adipose mass. Leptin receptor mRNA has been found in the hypothalamus-anterior pituitary in the pig which indicates that leptin could act at the brain and (or) pituitary gland to regulate LH secretion. Barb et al. (1997) showed that leptin treatment increased gonadotrophin secretion from pig pituitary cells in culture. Leptin may serve as a signal of nutritional status and may act directly on the brain or may possibly have a direct effect on the ovary, as leptin receptors have been found on the pig ovary (Ruiz-Cortes et al., 2000). Leptin expression in gilts in the present experiment, measured by ob mRNA gene expression in the s.c. backfat depot at the P2 position on day 19 of the oestrous cycle, was 30 times higher in gilts fed the high diet (Hepburn, 2002). This increase in leptin expression is consistent with results reported in humans (Considine et al., 1995) who received increased feed intake.

In conclusion, the present study has demonstrated that the ovarian follicle of the gilt is sensitive to changes in maternal nutrient intake. Given that the experimental diet used in the present study has been shown to increase embryo survival in pigs, it is probable that such diets would lead to an alteration in oocyte quality, which in turn would be expected to improve embryo survival. Several associated changes have been identified that act indirectly or directly on the ovary to alter follicular fluid composition. Further studies are required to establish which of these alterations are causal in the observed effects on oocyte maturation rate, but it is likely that alteration of oestradiol concentration in the follicular fluid is one of the candidates responsible.

This work was supported by Defra, Meat and Livestock Commission and JSR Healthbred Ltd in the LINK Sustainable Livestock Production programme. The authors wish to thank R. Walker and The Joint Animal Breeding Unit at the University of Nottingham for technical assistance with pig work, and A. Thain, M. Ewen, I. McKay, J. Slevin, D. Scholey and L. Beattie for their help with analysis of blood samples. The authors wish to thank NIDDKs National Hormone and Pituitary Program and A. F. Parlow for their kind donation of $\mathrm{pFSH}$ and $\mathrm{pLH}$ used in this study.

\section{References}

Ashworth CJ, Antipatis C and Beattie L (1995) Effect of pre- and postmating nutritional status on embryo survival and uterine function in the pig Journal of Reproduction and Fertility Abstract Series 1527

Ashworth CJ, Ross AW and Flint APF (1996) Inter-relationships of protein and oestradiol secretion by conceptuses and endometrium from Meishan pigs on days 11-15 of pregnancy Animal Reproduction Science 43123 135

Ashworth CJ, Antipatis C and Beattie L (1999a) Effects of pre- and postmating nutritional status on hepatic function, progesterone concentration, uterine protein secretion and embryo survival in Meishan pigs Reproduction, Fertility and Development 11 67-73

Ashworth CJ, Beattie L, Antipatis C and Vallet J (1999b) Effects of preand post-mating feed intake on blastocyst size, secretory function and glucose metabolism in Meishan gilts Reproduction, Fertility and Development 11 323-327

Barb C, Barrett J, Kraeling RR, Rampacek G, Yan X and Ramsay T (1997) Leptin modulation of luteinizing hormone $(\mathrm{LH})$ secretion by pig pituitary cells in culture. In Control of Pig Reproduction V pp 81 Eds G Foxcroft, $\mathrm{R}$ Geisert and C Doberska. Journals of Reproduction and Fertility Ltd, UK

Blache D, Tellam R, Chagas L and Blackberry M (2000) Level of nutrition affects leptin concentrations in plasma and cerebrospinal fluid in sheep Journal of Endocrinology 165 625-637

Booth P, Craigon J and Foxcroft G (1994) Nutritional manipulation of growth and metabolic and reproductive status in pre-pubertal gilts Journal of Animal Science 72 2415-2424

Britt J, Armstrong J, Cox N and Esbenshade K (1985) Control of follicular development during and after lactation in sows Journal of Reproduction and Fertility Supplement 33 37-54

Comin A, Gerin D, Cappa A, Marchi V, Renaville R, Motta M, Fazzini U and Prandi A (2002) The effect of an acute energy deficit on the hormone profile of dominant follicles in dairy cows Theriogenology $\mathbf{5 8}$ 899-910

Considine R, Considine E and Williams C (1995) Ob gene-expression is increased in adipocytes from obese humans Diabetes Supplement $\mathbf{4 4}$ A202

Cosgrove J, Tilton J, Hunter M and Foxcroft G (1992) Gonadotrophinindependent mechanisms participate in ovarian responses to realimentation in feed restricted pre-pubertal gilts Journal of Reproduction and Fertility 98 736-745

Cox NM, Stuart MJ, Althen TG, Bennett WA and Miller H (1987) Enhancement of ovulation rate in gilts by increasing dietary energy and administering insulin during follicular growth Journal of Animal Science 64 507-516

Flowers B, Martin MJ, Cantley TC and Day BN (1989) Endocrine changes associated with dietary-induced increase in ovulation rate (flushing) in gilts Journal of Animal Science 67 771-778

Foxcroft GR, Shaw HJ, Hunter MG, Booth PJ and Lancaster RT (1987) Relationships between luteinizing hormone, follicle stimulating hormone and prolactin secretion and ovarian follicular development in the weaned sow Biology of Reproduction 36 175-191

Fraker PJ and Speck JC (1978) Protein and cell membrane iodinations with a sparingly soluble chloroamide, 1,3,4,6-tetrachloro-3a, 6adiphenylglycoluril Biochemical and Biophysical Research Communications $80849-857$

Hepburn NL (2002) Regulation of Leptin Gene Expression in Pigs PhD Thesis, University of Aberdeen, UK

Hunter RHF and Polge C (1966) Maturation of follicular oocytes in the pig after injection of human chorionic gonadotrophin Journal of Reproduction and Fertility 12 525-531

Hunter MG, Southee JA, McLeod M and Haresign W (1986) Progesterone pre-treatment has a direct effect on $\mathrm{GnRH}$-induced preovulatory follicles to determine their ability to develop into normal corpora lutea in anoestrous ewes Journal of Reproduction and Fertility 76 349-363

Keim N, Stern J and Havel P (1998) Relation between circulating leptin concentrations and appetite during a prolonged, moderate energy deficit in women American Journal of Clinical Nutrition 68 794-801 
Kolaczynski J, Ohannesian J, Considine R, Marco C and Caro J (1996) Response of leptin to short term prolonged overfeeding in humans Journal of Clinical Endocrinology Metabolism 81 4162-4165

Mann GE, Lamming GE and Fray MD (1995) Plasma oestradiol and progesterone concentration during early pregnancy in the cow and the effects of treatment with buserelin Animal Reproduction Science 37 121-131

May J and Schomberg D (1981) Granulosa cell differentiation in vitro: effects of insulin on growth and functional integrity Biology of Reproduction 25 421-431

Mendoza C, Ruiz-Requena E, Ortega E, Cremades N, Martinez F, Bernabeu R, Greco E and Tesarik J (2002) Follicular fluid markers of oocytes developmental potential Human Reproduction 17 1017-1022

Moor R and Dai Y (2001) Maturation of pig oocytes in vivo and in vitro. In Control of Pig Reproduction Supplement VI, pp 91-104 Eds RD Geisert, $\mathrm{H}$ Niemann and C Doberska. Society for Reproduction and Fertility, Cambridge, UK

NRC (1998) Nutrient Requirements of Swine. 10th revised Edn. National Academy Press, Washington

O'Callaghan D and Boland MP (1999) Nutrition effects on ovulation, embryo development and the establishment of pregnancy in ruminants Animal Science 68 299-314

Otani T, Maruo T and Yukimura N (1985) Effect of insulin on porcine granulosa cells - implications of a possible receptor mediated action Acta Endocrinology Copenhagen 108 104-110

Owens P, Johnson R, Campbell R and Ballard F (1990) Growth hormone increases insulin-like growth factor-I (IGF-I) and decreases IGF-II in plasma of growing pigs Journal of Endocrinology 124 269-275

Pickard AR (1996) The Establishment of Pregnancy in Prolific Chinese Meishan and Large White X Landrace Gilts: A Comparative Study PhD Thesis, University of Aberdeen, Aberdeen, UK

Pope WF and First NL (1985) Factors affecting the survival of pig embryos Theriogenology 23 91-105

Pope WF, Lawyer MS, Nara BS and First NL (1986) Effect of asynchronous superinduction on embryo survival and range of blastocyst development in swine Biology of Reproduction 35 133-137

Prime GR and Symonds HW (1993) Influence of plane of nutrition on portal blood flow and the metabolic clearance rate of progesterone in ovariectomised gilts Journal of Agricultural Science 121 389-397

Quesnel H, Prasquier A, Mounier A and Prunier A (1998) Influence of feed restriction during lactation on gonadotrophic hormones and ovarian development in primiparous sows Journal of Animal Science $\mathbf{7 6}$ 856863

Rensis FD, Hunter MG and Foxcroft GR (1993) Suckling-induced inhibition of luteinizing hormone secretion and follicular development in the early postpartum sow Biology of Reproduction 48 964-969
Riad-Gabriel M, Jinagouda S, Sharma A, Boyadjian R and Saad M (1998) Changes in plasma leptin during the menstrual cycle European Journal of Endocrinology 139 528-531

Ruiz-Cortes Z, Men T, Palin M, Downey B, Lacroix D and Murphy B (2000) Porcine leptin receptor: molecular structure and expression in the ovary Molecular Reproduction and Development 56 465-474

Sirotkin AV, Taradajnik TE, Makarevich AV and Bulla J (1998) Effect of follicular cells, IGF-I and tyrosine kinase blockers on oocyte maturation Animal Reproduction Science 51 333-344

Starr JI, Horwitz DL, Rubenstein AH and Mako ME (1979) Insulin, proinsulin and c-peptide. In Methods of Hormone Radioimmunoassay Eds $B$ Jaffer and $\mathrm{H}$ Behman. Academic Press, London

Van de Leemput E, Van der Schans J, Vos A, Bevers $M$ and Dieleman S (1998) Follicular function as defined by estradiol-17 beta production determines in vitro developmental capacity of bovine oocytes derived from preovulatory-sized follicles Theriogenology $\mathbf{4 9} 300$

Veldhuis J, Furlanetto R, Juchter D, Garmey J and Veldhuis P (1985) Trophic actions of human somatomedin C/insulin-like growth factor I on ovarian cells: in vitro studies with swine granulosa cells Endocrinology $\mathbf{1 1 6}$ 1235-1242

Webb R, Baxter G, McBride D, Nordlom GD and Shaw MPK (1985) The measurement of testerone and oestradiol- $17 \beta$ using iodinated tracers and incorporating an affinity chromatography extraction procedure Journal of Steroid Biochemistry 23 1043-1051

Wieghart M, Slepetis R, Elliot J and Smith D (1986) Glucose absorption and hepatic gluconeogenesis in dairy cows fed diets varying in forage content Journal of Nutrition 116 839-850

Yang H, Foxcroft GR, Pettigrew JE, Johnston LJ, Shurson GC, Costa AN and Zak LJ (2000) Impact of dietary lysine intake during lactation on follicular development and oocyte maturation after weaning in primiparous sows Journal of Animal Science 78 993-1000

Zak LJ, Cosgrove JR, Aherne FX and Foxcroft GR (1997a) Pattern of feed intake and associated metabolic changes differentially affect postweaning fertility in primiparous lactating sows Journal of Animal Science $75208-216$

Zak LJ, Xu X, Hardin RT and Foxcroft GR (1997b) Impact of different patterns of feed intake during lactation in the primiparous sow on follicular development and oocyte maturation Journal of Reproduction and Fertility 110 99-106

Received 4 February 2003.

First decision 5 March 2003.

Revised manuscript received 2 April 2003.

Accepted 8 April 2003. 